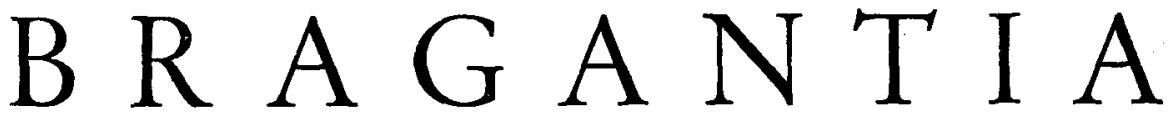

Boletim Científico do Instituto Agronómico do Estado de Sáo Paulo

Vol. 25

\title{
EFEITO DA ADUBAÇÃO VERDE COM UMA GRA- MÎNEA E QUATRO LEGUMINOSAS SÔBRE A PRODUÇÃO DO FEIJOEIRO "DA SECA", EM TERRA-ROXA-MISTURADA ( $\left.{ }^{1}\right)$
}

Shiro Miyasaka, engenheiro-agrônomo, Seção de Leguminosas, E. S. Freire, engenheiro-agrônomo $\left({ }^{2}\right)$, H. A. A. MASCARENHAS, engenheiro-agrônomo, Seção de Leguminosas, Clóvis Nery, engenheiro-agronômo (3), Mário CaMPaNA, engenheiro-agrônomo, Estação Experimental de Jaú, e GuIDo DE SoRDI, engenheiro-agrônomo, Estação Experimental de Ribeirão Prêto, Instituto Agronômico

\section{SINOPSE}

O efeito da adubação verde com uma gramínea e quatro leguminosas na cultura do feijoeiro "da sêca" foi estudado em quatro experiências instaladas em terra-roxa-misturada, no Estado de São Paulo. Os adubos verdes foram semeados em outubro e cortados com 2,5 a 3 meses de idade, tendo sido o feijoeiro plantado entre 12 de fevereiro e 4 de março. As áreas experimentais receberam adubação mineral uniforme.

Em média das quatro experiências, a testemunha produziu $374 \mathrm{~kg} / \mathrm{ha}$. Enquanto o efeito do sorgo forrageiro foi pràticamente nulo e os aumentos de produção provocados por lablabe, tefrósia e guandu variaram entre 158 e $185 \mathrm{~kg} / \mathrm{ha}$, o proporcionado pela crotalária (C. juncea L.) atingiu $318 \mathrm{~kg} / \mathrm{ha}$ ou $85 \%$.

\section{1 - INTRODUÇÃO}

No Estado de São Paulo, a adubação verde com leguminosas tem proporcionado resultados satisfatórios em culturas como a de milho (2) e de algodoeiro $(3,4,6)$. Todavia, êsse método de adubação apresenta um grande inconveniente, sobretudo para os agricultores que dispõem de áreas limitadas, pois que as leguminosas usadas para êsse fim são geralmente plantadas em outubro e cortadas em fevereiro ou março (durante o florescimento), ocupando, assim, a parte mais importante no ano agrícola.

(1) Recebido para publicacão em 27 de abril de 1966.

(2) Contratado pelo Conselho Nacional de Pesquisas, para colaborar com técnicos do Instituto Agronômico. Sua colaboração no presente trabalho foi prestada na apresentação e interpretação dos resultados obtidos.

(3) Chefe da Estação Experimental de São Simão, do Ministério da Agricultura. 
Procurando contornar êsse inconveniente, Miyasaka e colaboradores $(\mathbf{7}, \mathbf{8})$ experimentaram, com ótimos resultados, o emprêgo, na ocasião do plantio do feijoeiro, de matéria orgânica produzida em áreas outras que não a destinada a essa cultura.

Sendo o feijoeiro normalmente plantado em dois períodos do ano agrícola - o "das águas" (primavera-verão) e o "da sêca" (outono-inverno) - resolveu-se estudar, também, a possibilidade de usar, no último período, a adubação verde com plantas cultivadas nas mesmas áreas que, posteriormente, deveriam ser ocupadas pela leguminosa em aprêço.

Para isso, os adubos verdes seriam plantados na época recomendada, mas cortados em janeiro, isto é, muito antes do florescimento. Embora bem menor, a produção de massa verde aparentemente seria suficiente para o feijoeiro, mesmo porque, sendo mais tenra, sua decomposição, segundo Waksman (11), se processaria com maior rapidez. Êsse método de adubação, aliás, já foi experimentado, com êxito, por Guazelli (5).

No presente trabalho são apresentados os resultados de quatro experiências, realizadas em diferentes localidades do Estado de São Paulo, no ano agrícola 1964-65, nas quais foi estudado o comportamento de diversos adubos verdes, usados nas condições mencionadas no parágrafo anterior.

\section{2 - MATERIAIS E MÉTODOS}

Em blocos ao acaso, com seis repetições, foram comparados, além do testemunha, cinco tratamentos com adubos verdes (quatro leguminosas e uma gramínea). As leguminosas foram lablabe (Dolichos lablabe L.), guandu (Cajanus cajan (L.) Millsp.), tefrósia (Tephrosia candida DC) e crotalária (Crotalaria juncea L.); a gramínea, sorgo forrageiro (Sorghum vulgare Pers.).

Os canteiros, com $20 \mathrm{~m}^{2}$ de área, constaram de dez fileiras com $10 \mathrm{~m}$ de extensão e espaçamento de $40 \mathrm{~cm}$. Para lablabe e guandu, a distância entre as covas da mesma fileira foi de $20 \mathrm{~cm}$, e usaram-se duas sementes por cova. De tefrósia, crotalária e sorgo empregaram-se, por metro linear, respectivamente, 3,3 e $1,5 \mathrm{~g}$ de sementes (em média, 106, 213 e 115 sementes).

Conforme a localidade, os adubos verdes foram semeados entre 9 e 28 de outubro de 1964 e cortados entre 18 de janeiro e 9 de fevereiro de 1965, com 2,5 a 3 meses de idade. Após a pesagem, foram uniformemente espalhados nos canteiros que os produziram. A incorporação ao solo, com enxadão, foi efetuada cêrca de dez dias depois do corte. Nessa ocasião também se incorporou, da mesma maneira, a vegetação espontânea que se desenvolveu nos canteiros testemunhas. 
O feijoeiro foi semeado entre 12 de fevereiro e 4 de março de 1965, com o mesmo espaçamento entre as fileiras $(40 \mathrm{~cm})$ usado para os adubos verdes. Contudo, para observações e colheita aproveitaram-se somente as quatro fileiras centrais ou $8 \mathrm{~m}^{2}$. As covas ficaram distanciadas de $15 \mathrm{~cm}$, e cada uma recebeu duas sementes. Não se fêz desbaste.

As quatro experiências foram conduzidas em Botucatu, Jaú, Ribeirão Prêto e São Simão. Na última localidade, usou-se a variedade Prêto G-1; nas demais, a variedade Creme. Todos os canteiros experimentais (inclusive os que ficaram sem adubação verde) receberam $100 \mathrm{~kg} / \mathrm{ha}$ de $\mathrm{P}_{2} \mathrm{O}_{5}$ na forma de superfosfato simples. Em Jaú e Ribeirão Prêto, além da adubação fosfatada empregaram-se $40 \mathrm{~kg} / \mathrm{ha}$ de $\mathrm{N}$ como sulfato de amônio e $45 \mathrm{~kg} / \mathrm{ha}$ de $\mathrm{K}_{2} \mathrm{O}$ como cloreto de potássio. Em Botucatu e São Simão, aplicou-se a adubação mineral no plantio dos adubos verdes; em Jaú e Ribeirão Prêto, no do feijoeiro.

No quadro 1 se encontram os resultados analíticos de amostras compostas dos solos das áreas utilizadas. Tôdas as experiências foram instaladas em terra-roxa-misturada. Outras informações sôbre a execução das experiências serão mencionadas ao serem apresentados os resultados obtidos.

QAuDro 1. - Adubos verdes para o feijoeiro "da sêca". Resultados analíticos de amostras compostas dos solos utilizados para as experiências conduzidas, em 1964-65, nas localidades indicadas

\begin{tabular}{|c|c|c|c|c|c|}
\hline $\begin{array}{l}\text { Caracteristicas } \\
\text { determinadas (1) }\end{array}$ & Botucatu & Jaú & $\begin{array}{l}\text { Ribeirão } \\
\text { Prêto }\end{array}$ & São & Simão \\
\hline pH intern. $\ldots \ldots \ldots \ldots \ldots$ & 5,00 & 5,45 & 5,50 & & 5,15 \\
\hline $\mathrm{C}, \% \quad \ldots \ldots \ldots$ & 1,20 & 0,90 & 2,00 & & 1,40 \\
\hline $\mathrm{PO}_{4}---$, e.mg (2) & 0,07 & 0,22 & 0,14 & & 0,06 \\
\hline $\mathrm{K}^{+}$, e.mg ( $\left.{ }^{3}\right)$ & 0,16 & 0.22 & 0,20 & & 0,24 \\
\hline $\mathrm{Ca}^{++}+\mathrm{Mg}^{++}$, e.mg $\ldots$ & 5,20 & 3,20 & 6,20 & & 5,20 \\
\hline $\mathrm{AI}+++$, e.mg $\left(^{3}\right)$ & 0,30 & 0,20 & 0,20 & & 0,75 \\
\hline
\end{tabular}

(1) Análises efetuadas na Seção de Fertilidade do Solo, Instituto Agronômico. (2) Solúvel em $\mathrm{H}_{2} \mathrm{SO}_{4} 0,05 \mathrm{~N}+\mathrm{HCl} 0,025 \mathrm{~N}$ por $100 \mathrm{ml}$ de T.F.S.A. (3) Trocáveis, por $100 \mathrm{ml}$ de T.F.S.A. 


\section{3 - EXECUÇÃO E RESULTADOS}

As produções de massa aérea dos adubos verdes e sementes de feijão se acham no quadro 2.

\section{1 - EXPERIENCIA DE BOTUCATU}

Instalada na Estação Experimental de Botucatu, do Ministério da Agricultura $\left({ }^{4}\right)$, numa área cultivada, no ano agrícola anterior, com milho moderadamente adubado.

$\mathrm{Na}$ análise estatística da produção de massa verde, o coeficiente de variação correspondeu a $17,9 \%$. De acôrdo com o teste de Tukey, a crotalária foi significativamente superior a todos os adubos verdes, e o sorgo a guandu, lablabe e tefrósia. Guandu superou tefrósia, mas não diferiu de lablabe, que, por sua vez, se mostrou equivalente a tefrósia.

Os adubos verdes, que foram incorporados ao solo poucos dias antes do plantio do feijoeiro, prejudicaram a germinação dêste, tendo a redução provocada pela crotalária atingido $17 \%$. No "stand" final, não se notou redução nos canteiros que tiveram guandu e tefrósia, mas os adubados com sorgo, lablabe e crotalária sofreram baixas de 10 a $14 \%$.

$\mathrm{Na}$ análise da produção de feijão, o coeficiente de variação se elevou a $40,5 \%$, mas houve diferenças altamente significativas entre os tratamentos. Em relação ao tratamento sem adubo verde, o sorgo deprimiu ligeiramente a produção, ao passo que lablabe, tefrósia, guandu e crotalária a aumentaram de, respectivamente, 92, 129, 187 e $454 \mathrm{~kg} / \mathrm{ha}$. De acôrdo com o teste de Dunnett, o aumento proporcionado pela crotalária, correspondente a $160 \%$, foi o único significativo. Pelo teste de Tukey ao nível de 5\%, lablabe, tefrósia e guandu mostraram-se estatìsticamente equivalentes, mas as duas primeiras leguminosas foram significativamente inferiores à crotalária.

Note-se que, apesar de ter sido o adubo verde mais prejudicial à germinação e ao "stand" final do feijoeiro, a crotalária se destacou como o mais benéfico à sua produção.

\section{2 - EXPERIENCIA DE JAÚ}

Conduzida na Estação Experimental “Hélio de Moraes", do Instituto Agronômico, numa área que havia tido, no ano anterior, algodão adubado com NPK. 
Conquanto fôssem cortados com cêrca de 2,5 meses de idade, os adubos verdes, à exceção de tefrósia, produziram boa quantidade de massa aérea. Nessa produção, embora o coeficiente de variação tenha atingido $30 \%$, houve diferenças altamente significativas entre os tratamentos. Segundo o teste de Tukey, sorgo e crotalária, com produções de 66,7 e 55,9 t/ha, mostraram-se estatisticamente equivalentes e foram superiores aos demais adubos verdes. Lablabe e guandu, bem como guandu e tefrósia, também se mostraram equivalentes, sendo que tefrósia foi inferior a lablabe.

Talvez porque foram cortados 39 dias antes do plantio do feijoeiro, os adubos verdes pouco prejudicaram a germinação e melhoraram substancialmente os "stands" finais. As produções de feijão foram baixas, e o coeficiente de variação correspondeu a $26,9 \%$, não tendo havido diferenças significativas entre os tratamentos. Observaram-se, porém, apreciáveis efeitos relativos dos adubos verdes, os quais se elevaram de +26 e $+35 \%$, nos casos de tefrósia e guandu, a +53 e $+60 \%$, nos de crotalária e lablabe. O devido ao sorgo ocupou posição intermediária, com $+41 \%$.

QuAdro 2. - Adubos verdes para o feijoeiro "da sêca". Produçōes de massa aérea dos adubos verdes recém-cortados, em toneladas por hectare, e de sementes de feijăo sêcas ao ar, em quilogramas por hectare, obtidas nas experiências conduzidas nas localidades indicadas. Os adubos verdes foram semeados em outubro de 1964 e cortados com 2,5 a 3 meses de idade. O feijoeiro foi plantado entre 12 de fevereiro e 4 de março de 1965

\begin{tabular}{|c|c|c|c|c|}
\hline Adubos verdes & Botucatu & Jaú & Rib. Prêto & São Simão \\
\hline \multicolumn{5}{|l|}{ Massa verde, t/ha } \\
\hline Lablabe $\ldots \ldots \ldots \ldots \ldots \ldots$ & 9,7 & 33,0 & 42,2 & 43,1 \\
\hline$\ldots \ldots \ldots \ldots \ldots \ldots$ & 14,6 & 16,7 & 36,6 & 23,9 \\
\hline Tefrósia $\quad \ldots \ldots \ldots \ldots \ldots \ldots$ & 7,1 & 2,6 & 18,8 & 15,7 \\
\hline Crotalária $\ldots \ldots \ldots$ & 45,5 & 55,9 & 68,7 & 59,2 \\
\hline Sorgo $\ldots \ldots \ldots \ldots \ldots \ldots \ldots$ & 21,1 & 66,7 & 75,0 & 74,6 \\
\hline \multicolumn{5}{|l|}{ Feijäo, $k g / h \alpha$} \\
\hline Lablabe & 375 & 385 & 756 & 611 \\
\hline Guandu & 470 & 325 & 876 & 564 \\
\hline Tefrósia $\ldots$. & 412 & 302 & 734 & 683 \\
\hline Crotaläria $\quad$. & 737 & 367 & 840 & 824 \\
\hline Sorgo $\ldots \ldots \ldots \ldots \ldots \ldots$ & 255 & 338 & 548 & 419 \\
\hline Testemunha (sem adubo ver- & & & & \\
\hline de) $\ldots \ldots \ldots \ldots \ldots \ldots \ldots$ & 283 & 240 & 628 & 344 \\
\hline
\end{tabular}




\section{3 - EXPERIENCIA DE RIBEIRÃO PRETTO}

Instalada na Estação Experimental de Ribeirão Prêto, do Instituto Agronômico, numa área que teve, no ano anterior, sorgo forrageiro adubado com NPK.

As produções de massa verde foram geralmente boas e cresceram, significativamente (Tukey), de tefrósia para guandu, lablabe, crotalária e sorgo. O coeficiente de variação foi de apenas $6 \%$.

Conquanto os adubos verdes fôssem cortados 45 dias antes do plantio do feijoeiro, a germinação dêste sofreu redução de $16 \%$ no tratamento com crotalária. No "stand" final, porém, essa redução baixou para $7 \%$. $\mathrm{Na}$ produção de sementes, o coeficiente de variação foi de $20 \%$, e o teste $\mathrm{F}$, significativo ao nível de $1 \%$. Em relação ao testemunha, enquanto o efeito do sorgo foi negativo $(-80 \mathrm{~kg} / \mathrm{ha}$ ou $-13 \%)$, os de tefrósia, lablabe, crotalária e guandu se elevaram a, respectivamente, $+106,+128,+212$ e $+248 \mathrm{~kg} / \mathrm{ha}(+17,+20,+34$ e $+39 \%)$. Segundo o teste de Dunnett, sòmente o último efeito (o do guandu) alcançou significância. As quatro leguminosas foram estatisticamente (Tukey) equivalentes, ao passo que o sorgo se mostrou inferior ao guandu e à crotalária.

Tendo ocorrido pequeno período sêco antes da floração, iniciada em 15 de abril, nessa data determinou-se a umidade existente no solo, nas camadas de 0-30 e $30-60 \mathrm{~cm}$. Não se notou diferença entre as duas camadas. Em média destas e em relação ao testemunha, que tinha $26,3 \%$, o teor de umidade era ligeiramente superior $(27,6 \%)$ nos canteiros adubados com sorgo e ligeiramente inferior $(24,8$ e $25,3 \%)$ naqueles que receberam tefrósia ou crotalária. Os adubados com lablabe e guandu não diferiram do sem adubo verde.

\section{4 - EXPERIENCIA DE SÃO SIMÃO}

Esta foi conduzida na Estação Experimental de São Simão, do Ministério da Agricultura, em solo de cerrado anteriormente cultivado com milho e algodão adubados.

Os adubos verdes, que foram cortados aos três meses de idade, desenvolveram-se muito bem. O coeficiente de variação correspondeu a $17,7 \%$, e o teste $\mathrm{F}$ revelou haver diferenças significativas ao nível de 1\%. De acôrdo com o teste de Tukey, o sorgo se mostrou significativamente superior à crotalária; a crotalária, ao lablabe; o lablabe, ao guandu e à tefrósia. Os dois últimos adubos não diferiram estatìsticamente.

Embora os adubos verdes tenham sido incorporados ao solo $\mathbf{1 6}$ dias antes do plantio do feijoeiro, os "stands" iniciais dêste foram até ligeiramente beneficiados por tefrósia, guandu e lablabe. Entretanto, sorgo e crotalária provocaram reduções de, respectiva- 
mente, 16 e $10 \%$, tanto nos "stands" iniciais como nos finais. As plantas adubadas com sorgo também se apresentavam muito pálidas.

$\mathrm{Na}$ análise da produção do feijoeiro, o coeficiente de variação atingiu $32,7 \%$, mas houve diferenças altamente significativas entre os tratamentos. Em relação ao testemunha, sorgo, guandu, lablabe, tefrósia e crotalária aumentaram a produção de, respectivamente, 75, 220, 267, 339 e $480 \mathrm{~kg} / \mathrm{ha}$. Dêsses aumentos, sòmente os dois últimos, proporcionados por tefrósia e crotalária, alcançaram o nível de significância pelo teste de Dunnett. Na comparação entre os adubos verdes, pelo teste de Tukey ao nível de $5 \%$, as quatro leguminosas se mostraram equivalentes. O sorgo foi inferior à crotalária, mas não diferiu estatisticamente das demais leguminosas.

QUADro 3. - Adubos verdes para o feijoeiro "da sêca". Resultados médios das três experiências (de Botucatu, Ribeirão Prêto e São Simão), cujas produções de sementes de feijão foram analisadas em conjunto

\begin{tabular}{|c|c|c|c|c|c|}
\hline \multirow{4}{*}{ Tratamentos } & \multicolumn{4}{|c|}{ Feijão } & \multirow{3}{*}{$\begin{array}{l}\text { Massa } \\
\text { aérea dos } \\
\text { adubos } \\
\text { verdes }\end{array}$} \\
\hline & \multirow{2}{*}{\multicolumn{2}{|c|}{$\begin{array}{l}\text { Produções de } \\
\text { sementes }\end{array}$}} & \multicolumn{2}{|c|}{ "Stands" } & \\
\hline & & & Iniciais & Finais & \\
\hline & $\mathrm{kg} / \mathrm{ha}$ & fndices & Indices & fndices & $t / h a$ \\
\hline Crotalária & 800 & 191 & 85 & 90 & 57,8 \\
\hline Guandu & 637 & 152 & 100 & 104 & 25,0 \\
\hline Tefrósia & 610 & 146 & 99 & 102 & 13,9 \\
\hline Lablabe $\ldots .$. & 581 & 139 & 97 & 97 & 31,7 \\
\hline Sorgo & 408 & 98 & 93 & 90 & 56,9 \\
\hline Sem adubo verde & 418 & 100 & 100 & 100 & - \\
\hline
\end{tabular}

\section{5 - ANÁLISE CONJUNTA}

Por apresentar variância diferente das demais, a experiência de Jaú foi excluída da análise conjunta da produção de feijão. As médias das outras três localidades constam do quadro 3.

$\mathrm{O}$ coeficiente de variação dêsse conjunto correspondeu a $29,4 \%$, e a interação tratamentos $\times$ localidades não alcançou significância. Enquanto o sorgo deprimiu ligeiramente a produção de sementes, os aumentos proporcionados por crotalária, guandu, tefrósia e lablabe, todos significativos segundo Dunnett, atingiram, respectivamente, $382,219,192$, e $163 \mathrm{~kg} / \mathrm{ha}$ ou $91,52,46$ e $39 \%$ da 
produção do tratamento sem adubo verde. Comparando as quatro leguminosas, verifica-se que, de acôrdo com o teste de Tukey ao nível de $5 \%$, as três últimas se mostraram estatisticamente equivalentes, e foram inferiores à crotalária.

Do quadro 3 também constam as médias dos "stands" do feijoeiro. Observa-se que a crotalária, embora tenha sido o melhor adubo verde para a produção do feijoeiro, foi o que mais prejudicou seus "stands", ocasionando redução de $15 \%$ no "stand" inicial. É verdade que, no "stand" final, em conseqüência da morte de plantas no tratamento testemunha, a redução atribuída à crotalária foi atenuada para $10 \%$. Deve-se notar, contudo, que, enquanto lablabe pràticamente não afetou o "stand" final, guandu e tefrósia o melhoraram um pouco.

Para comparação, no quadro 3 figuram, ainda, as médias das produções de massa aérea dos adubos verdes. Verifica-se que essas produções não mantiveram relação consistente com as de sementes de feijão, mesmo considerando-se sòmente as leguminosas.

Convém registrar que a inclusão da experiência de Jaú não modificaria substancialmente os resultados médios que acabam de ser estudados. Na produção de sementes, por exemplo, os índices das médias das quatro experiências, referentes a crotalária, guandu, tefrósia, lablabe e sorgo, seriam, respectivamente, 185, 149, 143, 142 e 104. A posição dos diversos adubos verdes seria, portanto, sensivelmente a mesma do quadro 3 .

\section{6 - INFLUENCIA SÔBRE ALGUMAS CARACTERÍSTICAS DO SOLO}

Após a colheita foram tiradas, de cada canteiro, quatro amostras superficiais $(0-20 \mathrm{~cm})$ do solo, as quais, uma vez misturadas, formaram a amostra composta destinada à análise. Assim, de cada tratamento foram analisadas seis amostras.

Em vista da época dessa amostragem, não se poderia esperar que a análise revelasse o que aconteceu durante o período de mais ativa decomposição dos adubos verdes e de desenvolvimento do feijoeiro. Além disso, os elementos determinados nas análises não foram suficientes para explicar as diferenças observadas no comportamento dos diversos adubos verdes nas localidades estudadas. Por êsses motivos, e porque as informações disponíveis não permitissem estudo mais detalhado, no quadro 4 são apresentadas apenas as médias dos resultados obtidos nas quatro localidades (24 repetiçôes para cada tratamento), as quais servirão de base para uma apreciação sumária do assunto.

$\mathrm{O} \mathrm{pH}$ e o teor de fósforo solúvel não foram, pràticamente, modificados pela adubação verde.

A porcentagem de carbono sofreu pequena elevação, que atingiu $10 \%$ nos tratamentos com sorgo e crotalária. Convém lem- 
brar que êsse teor, bem como os demais, foi determinado na T.F.S.A. (terra fina, sêca ao ar), e que, portanto, não inclui os restos de caules e raízes ainda não suficientemente decompostos para fazerem parte da chamada matéria orgânica do solo.

As médias referentes ao teor trocável de cálcio + magnésio não representam bem o que se observou nas quatro localidades, pois em Botucatu e Jaú os adubos verdes provocaram ligeira depressão nesse teor, ao passo que em Ribeirão Prêto e São Simão proporcionaram aumentos que variaram entre 5 e $13 \%$.

Em contraste com as pequenas modificações assinaladas até aqui, foi relativamente enorme a influência dos adubos verdes sôbre a mobilização do potássio do solo. Os maiores aumentos médios, de 65 e $35 \%$, proporcionados, respectivamente, pelas adubações com sorgo e crotalária, foram muito consistentes. No caso do sorgo, êles variaram, nas quatro localidades, entre 38 e 110\%; no da crotalária, entre 14 e $50 \%$. Mesmo no caso do lablabe, que só aumentou o teor médio em $24 \%$, observaram-se acréscimos de 17, 19 e 70\%, em três localidades, e nenhuma modificação, na restante. Os aumentos atribuídos a guandu e tefrósia, além de pequenos, foram menos consistentes. Conforme esclarecido no capítulo 2, nas presentes experiências os adubos verdes foram incorporados ao solo dos canteiros que os produziram, não se tratando, por conseguinte, de adições provenientes de outros locais. Deve-se notar, ainda, que as amostras foram tiradas depois que o feijoeiro havia extraído o potássio necessário ao seu desenvolvimento.

QUADRo 4. - Adubos verdes para o feijoeiro "da sêca". Resultados analíticos (1) de amostras de solo tiradas por ocasião da colheita do feijoeiro. Os dados mencionados são médias das experiências conduzidas em quatro localidades, em cada uma das quais foram tiradas amostras das seis repetições de cada tratamento

\begin{tabular}{|c|c|c|c|c|c|c|}
\hline \multirow[b]{2}{*}{ Tratamentos } & \multirow[b]{2}{*}{$\begin{array}{l}\mathrm{pH} \\
\text { int. }\end{array}$} & \multirow[b]{2}{*}{$\begin{array}{l}\mathrm{C} \\
\%\end{array}$} & \multirow{2}{*}{$\begin{array}{l}\mathrm{PO}_{4}^{---} \\
\text {sol. (2) }\end{array}$} & \multicolumn{3}{|c|}{ Teores trocáveis $\left({ }^{3}\right)$} \\
\hline & & & & $\mathbf{K}^{+}$ & $\mathrm{Ca}+++\mathrm{Mg}++$ & $\mathrm{Al}+++$ \\
\hline Lablabe & 5,57 & 1,51 & 0,12 & 0,21 & 5,12 & 0,44 \\
\hline Guandu & 5,39 & 1,48 & 0,12 & 0,20 & 4,87 & 0,49 \\
\hline Tefrósia & 5,44 & 1,52 & 0,13 & 0,20 & 5,11 & 0,47 \\
\hline Crotalária & 5,44 & 1,53 & 0,11 & 0,23 & 5,02 & 0,46 \\
\hline Sorgo & 5,50 & 1,53 & 0,11 & 0,28 & 4,96 & 0,60 \\
\hline Sem adubo verde & 5,52 & 1,39 & 0,12 & 0,17 & 4,83 & 0,44 \\
\hline
\end{tabular}

(1) Análises efetuadas na seção de Fertilidade do Solo, Instituto Agronômico. (2) Solúvel em $\mathrm{H}_{2} \mathrm{SO}_{4} 0,05 \mathrm{~N}+\mathrm{HCl} 0,025 \mathrm{~N}$, em e.mg por $100 \mathrm{ml}$ de T.F.S.A. (3) Trocáveis, em e.mg por $100 \mathrm{ml}$ de T.F.S.A. 
O efeito do sorgo sôbre o teor de alumínio trocável também foi considerável, pois correspondeu a $+36 \%$, em média, e variou, nas quatro localidades, entre +31 e $+62 \%$. Guandu e crotalária também o aumentaram um pouco em três localidades e na média das quatro. Os efeitos de lablabe e tefrósia foram muito variados.

\section{4 - DISCUSSÃO E CONCLUSÕES}

Em média das quatro experiências, o sorgo aumentou a produção do feijoeiro de apenas $4 \%$, ao passo que lablabe, tefrósia, guandu e crotalária a aumentaram de, respectivamente, 42, 43, 49 e $85 \%$. Na média das três experiências que puderam ser analisadas em conjunto, a colocação dos diversos adubos verdes foi pràticamente a mesma, pois suas respostas, na ordem em que foram citados, corresponderam a $-2,+39,+46,+52$ e $+91 \%$. $\mathrm{Na}$ análise dêsse conjunto, a interação tratamentos $\times$ localidades não foi significativa, e enquanto o efeito do sorgo foi pràticamente nulo, os de lablabe, tefrósia, guandu e crotalária, todos significativos, elevaram-se a, respectivamente, $+163,+192,+219$ e +382 kg/ha. A crotalária foi significativamente superior às outras leguminosas, que, por sua vez, se mostraram equivalentes.

Apesar de ter produzido grande quantidade de massa orgânica, o sorgo, nas condições das experiências relatadas, comportou-se muito mal como adubo verde para o feijoeiro, provàvelmente devido à associação de dois fatôres negativos. Na maioria das experiências, essa gramínea reduziu apreciàvelmente os "stands". Além disso, notou-se que, nos tratamentos que o receberam, o feijoeiro se apresentava com a palidez característica da deficiência de nitrogênio, conhecido efeito imediato da aplicação de material orgânico com larga relação $\mathrm{C} / \mathrm{N}$ sôbre a imobilização do nitrogênio assimilável do solo (1).

É verdade que a crotalária, que se destacou como o adubo verde mais eficiente para a produção do feijoeiro, também causou, nos "stands", redução ainda mais acentuada que a provocada pelo sorgo. Nesse caso, porém, as plantas sobreviventes puderam dispor de considerável quantidade de nitrogênio ( $\mathrm{e}$, provàvelmente, de outros elementos essenciais), e se desenvolveram de tal maneira que ultrapassaram a produtividade daquelas que não receberam adubação verde.

É claro, porém, que os resultados obtidos com essa leguminosa teriam sido ainda melhores se ela não tivesse prejudicado os "stands". Convém, por isso, estudar a possibilidade de contornar êsse inconveniente.

Vários autores estrangeiros $(\mathbf{2}, \mathbf{1 0})$ têm mostrado que os produtos da decomposição dos adubos verdes com leguminosas podem prejudicar não sòmente a germinação, mas também o desenvolvi- 
mento inicial das culturas que os recebem. No Estado de São Paulo, Mendes (6) observou êsse inconveniente com tanta frequiência que passou a recomendar o enterrio da mucuna dois meses antes da semeação do algodoeiro.

A recomendação de Mendes (6) se baseia no corte da mucuna ao atingir seu máximo desenvolvimento, o que normalmente se verifica, em São Paulo, no início do período frio e sêco (abril), durante o qual sòmente parte da massa vegetal de decompõe. $\mathrm{Na}$ entrada do período quente e úmido (outubro), é que se processa, em ritmo acelerado, a decomposição da maior parte daquela massa. Assim, não obstante o longo intervalo entre o corte da leguminosa e os plantios da primavera, o risco de prejuízo não desaparece.

Nas presentes experiências, as leguminosas foram cortadas, conforme a localidade, entre 18 de janeiro e 9 de fevereiro, bem antes da floração (com 2,5 a 3 meses de idade). Estavam, portanto, bastante tenras, em condições de se decomporem ràpidamente (11). Tendo sido imediatamente espalhadas nos canteiros que as produziram, a parte inferior da camada vegetal ficou em contacto com o solo, e, com as contínuas e abundantes chuvas da época, mesmo antes da incorporação ao solo deve ter sofrido intensa decomposição, perdendo, assim, por lixiviação e volatilização, parte dos resultantes produtos tóxicos.

Acresce ainda que o tempo continuou chuvoso durante a germinação do feijoeiro, de sorte que, nos intervalos entre o corte das leguminosas e o término da germinação, de $23,31,46$ e 51 dias, respectivamente, nas experiências de Botucatu, São Simão, Jaú e Ribeirão Prêto, as precipitações totalizaram 275, 400, 651 e $595 \mathrm{~mm}$. Mesmo assim, os "stands" foram apreciàvelmente prejudicados.

A solução do problema mediante a dilatação dos intervalos corte-plantio ou incorporação-plantio apresenta séria dificuldade, pois as condições que favorecem a eliminação dos produtos tóxicos também concorrem para a perda dos elementos desejáveis, adicionados ou mobilizados pela adubação verde. Efetivamente, as respostas à adubação com crotalária caíram de $+160 \%$, em Botucatu, para $+140 \%$, em São Simão, +53\%, em Jaú, e +34\%, em Ribeirão Prêto, diminuindo, portanto, à medida que aumentaram os citados intervalos e as precipitações totais. Deve-se esclarecer que, além da adubação fosfatada, usada em tôdas as experiências, nas de Jaú e Ribeirão Prêto se empregou pequena dose de NK mineral, o que pode ter contribuído para diminuir, mas não de maneira tão drástica, o efeito da adubação verde, nessas localidades.

Essas considerações mostram que o assunto é muito complexo e só pode ser resolvido satisfatòriamente com meticulosa experimentação, tendo-se sempre em mente as condições climáticas do periodo anterior ao plantio do feijoeiro, pois as da safra "das águas" diferem muito das prevalecentes na safra "da sêca", e, 
ainda, que os intervalos entre o corte ou a incorporação ao solo da massa vegetal e o plantio do feijoeiro devem ser regulados de acôrdo com a espécie de leguminosa e a idade em que esta é cortada. Convém estudar, também, até que ponto as partes ainda não decompostas do material incorporado ao solo impedem ou dificultam a emergência das plantas.

\section{GREEN MANURES FOR DRY BEANS}

\section{SUMMARY}

Four experiments were conducted in different parts of the State of São Paulo to study the effect of some green manure species on the yield of dry beans in the fall planting period. The green manures were sown in October and cut about three months later. Dry beans were sown between February 12 and March 4 of the following year. All the experimental plots received mineral fertilizer.

In the average of the four experiments, the control plots produced 374 kilograms per hectare of air-dry beans. While the effect of Sorghum vulgare was practically null and those of Dolichos lablabe, Tephrosia candida and Cajanus cajan varied fron +42 to $+49 \%$, that of Crotalaria juncea reached $+85 \%$.

\section{LITERATURA CITADA}

1. Bear, Firman E. Soils and fertilizers. New York, John Wiley \& Sons, Inc., $1963.420 \mathrm{p}$.

2. Christidis, B. C. \& Harrison, G. J. Cotton growing problems. New York, McGraw-Hill Book Co., 1955. 633p.

3. Cavaleri, P. A., Fuzatto, M. G. \& Freire, E. S. Adubação do algodoeiro. XIV - Experiências com mucuna e adubos minerais. Bragantia $22:[331]-350.1963$.

4. Corrêa, D. M., Pettinelli, A., Venturini, W. R. \& Freire, E. S. Adubação do algodoeiro. XI - Ensaio com calcário, adubação verde e adubação mineral. Bragantia 20:[617]-633. 1961.

5. Guazelli, J. R. Problemas da cultura do feijão. Estação Experimental de Patos, MG, 1963. (Mimeografado)

6. Mendes, C. Teixeira. A cultura do algodoeiro. Rev. Agric., Piracicaba $9: 383-400.1934$.

7. Miyasaka, S., Camargo, A. Paes de, Inforzato, R. \& Igue, Toshio. Efeitos da cobertura e da incorporação ao solo, imediatamente antes do plantio, de diferentes formas de matéria orgânica não decomposta na cultura do feijoeiro. Bragantia:....... 1966.

8.— Freire, E. S. \& Mascarenhas, H. A. A. Efeito da matéria orgânica sôbre a produção do feijoeiro. Bragantia 24:LIX-LXI. 1965. 
9. Neme, N. A. Leguminosas para adubos verdes e forragens. Campinas, Instituto Agronômico, 1959. (Boletim n. ${ }^{\circ}$ 109)

10. Pieters, A. J. \& McKeE, R. The use of green manure crops. Yearbook of Agriculture, 1938. Washington, Department of Agriculture, 1938. p.431-444.

11. WaKsman, S. A. Chemical and microbiological principles underlying the decomposition of green manures in the soil. J. Amer. Soc. Agron. 21:1-18. 1929. 